\title{
Home Advantage and Sports Performance: Evidence, Causes and Psychological Implications*
}

\section{Competir en casa y rendimiento deportivo: evidencias, causas e implicaciones psicológicas}

Recibido: junio 13 de 2011 | Revisado: junio 10 de 2012 | Aceptado: julio 17 de 2012

\author{
Alejandro LegaZ-ARrese ** \\ Universidad de Zaragoza, España \\ Diego MOliner-URdiAleS **** \\ Universidad Jaume I, Castellón, España \\ Diego MunguíA-IZQUIERDO ***** \\ Universidad Pablo de Olavide, Sevilla, España
}

\section{doi:10.11144/Javeriana.UPSY12-3.hasp}

Para citar este artículo: Legaz-Arrese, A., MolinerUrdiales, D., \& Munguía-Izquierdo, D. (2013).

Home advantage and sports performance: Evidence, causes and psychological implications. Universitas Psychologica, 12(3), 933-943. doi:10.11144/ Javeriana.UPSY12-3.hasp

* The present manuscript is from a multicenter collaborative work among three research groups: "Movimiento Humano" from the Universidad de Zaragoza, "LIFE" from the Universidad Jaume I, and "Actividad Física, Salud y Deporte" from the Universidad Pablo de Olavide.

** Universidad de Zaragoza, España. ResearchID: H-8702-2013. Departamento de Fisiatría y Enfermería.E-mail: alegaz@unizar.es

**** Universidad Jaume I. Corresponding author: Diego Moliner-Urdiales. ResearchID: H-8689-2013. Faculty of Humanities and Social Sciences. Av Sos Baynat s/n. PC 12071. Castellón, Spain. E-mail: dmoliner@uji.es.

****** Universidad Pablo de Olavide, Sevilla, España. ResearchID: H-6452-2013. Departamento de Deporte e Informática.E-mail: dmunizq@upo.es

\section{A B S T R A C T}

Home advantage in competitive sports is well documented despite some contradictory results. Previous studies have identified 5 main causes of home advantage in competitive sports: crowd, familiarity, travels, rules and territoriality. Moreover, several studies have proposed the influence of these factors over psychological and behavioral states in athletes, coaches and referees. The present review summarizes the available scientific evidences about home advantage in sport and tries to identify the environmental and psychological causes of this phenomenon.

Key words authors

Home Advantage, Competition, Performance, Psychology.

Key words plus

Sport, Behaviour, Result.

\section{RESUMEN}

Competir de local constituye una ventaja ampliamente documentada en el ámbito deportivo. Los estudios previos han identificado cinco causas principales que permiten explicar la ventaja que ello supone: la presencia de aficionados, la familiaridad con el entorno, la ausencia de viajes, la aplicación de las normas y el sentimiento de territorialidad. Además, algunos estudios indican que estos factores influyen sobre el estado psicológico y el comportamiento tanto de los deportistas como de los entrenadores y árbitros. Esta revisión pretende recoger las actuales evidencias científicas sobre la ventaja que supone competir en casa, tratando de identificar las causas ambientales y psicológicas que explican este fenómeno en el ámbito deportivo.

Palabras clave autores

Ventaja local, competición, rendimiento, psicología.

Palabras clave descriptores

Deporte, comportamiento, resultados. 


\section{Introduction}

Over the years, researchers have endeavored to identify the factors that promote human performance during competitive sports. Human physical performance is multifactorial and determined by a range of environmental (e.g., training program, nutrition, and technological aids) and genetic factors (Brutsaert \& Parra, 2006; Davids \& Baker, 2007; Maughan, 2005; Smith, 2003; Williams \& Folland, 2008).

Home advantage in competitive sports is well documented and has been the topic of much research over the past 30 years, although its precise causes are not well understood (Carron, Loughhead, \& Bray, 2005; Courneya \& Carron, 1992; Nevill \& Holder, 1999; Pollard, 2006a). Despite the inconclusive results, several studies have found a positive association between the psychological and behavioral states previous to competitive events and home advantage (Bray, Martin, \& Widmeyer, 2000; Carre, Muir, Belanger, \& Putnam, 2006; Carron et al., 2005; Duffy \& Hinwood, 1997; Neave \& Wolfson, 2003; Polman, Nicholls, Cohen, \& Borkoles, 2007; Terry, Walrond, \& Carron, 1998; Thuot, Kavouras, \& Kenefick, 1998; Waters \& Lovell, 2002).

The present review summarises the available scientific evidences concerning home advantage in sports and attempts to identify its environmental and psychological causes.

\section{Evidence for home advantage in competitive sports}

Home advantage in sports, that is, the higher probability of success when playing at home than away from home, has received much attention within sports literature (Carron et al., 2005; Courneya \& Carron, 1992; Nevill \& Holder, 1999; Pollard, 2006a).

\section{Home Advantage and Competitive System}

Currently, it is possible to evaluate the existence of home advantage in different sports with different kinds of competitive systems:
1. Balanced competition; games are played under a balanced home and away schedule (e.g., soccer or baseball regular league).

2. Unbalanced competition; games are played under an unbalanced home and away schedule (e.g., grand-slam tennis tournament, major golf championships or FIFA World Cup).

Regarding balanced competitions, Pollard (1986) defined home advantage as the number of points won at home expressed as a percentage of all points gained, and Courneya and Carron (1992) identified home advantage as a term used to describe the consistent finding that home teams in sports competitions win over $50 \%$ of the games played. Bray (1999) specified and defined the concept of home advantage as occurring when the home winning percentage minus the away winning percentage is greater than $5 \%$. In relation to unbalanced competitions, Nevill, Holder, Bardsley, Calvert, and Jones (1997) defined home advantage as a significant improvement in performance achieved over expected performance (according to the world ranking or previous results) for local athletes/teams.

\section{Home Advantage and Team Sports}

Home advantage has been documented in a variety of different team sports including American football (Pollard \& Pollard, 2005b; Watson \& Krantz, 2003), Australian football (Clarke, 2005), baseball (Adams \& Kupper, 1994; Bray, Obara, \& Kwan, 2005; Pollard \& Pollard, 2005b; Watson \& Krantz, 2003), rugby (Morton, 2006), field hockey (Carre et al., 2006; Pace \& Carron, 1992), ice hockey (Agnew \& Carron, 1994; Dennis \& Carron, 1999; Pollard \& Pollard, 2005b), basketball (Moore \& Brylinsky, 1995; Pollard \& Pollard, 2005b; Steenland \& Deddens, 1997; Watson \& Krantz, 2003) and soccer (Barnett \& Hilditch, 1993; Brown, Van Raalte, Brewer, Winter, \& Cornelius, 2002; Clarke \& Norman, 1995; Nevill, Balmer, \& Williams, 1999; Nevill \& Holder, 1999; Nevill, Newell, \& Gale, 1996; Pollard, 1986, 2006b; Pollard \& Pollard, 
2005b; Thomas, Reeves, \& Davies, 2004; Wolfson, Wakelin, \& Lewis, 2005).

Another effect, which has received much less attention but is discussed by players, commentators, fans and coaches, has been recently identified; the second leg home advantage (Page \& Page, 2007). This effect describes the phenomenon in which, on average, teams are more likely to win a two-stageknock-out competition when they play at home in the second leg. That is, both teams have a home advantage, but this advantage is significantly greater for the team that plays at home second.

\section{Home Advantage and Individual Sports}

The prevalence of home advantage both in individual sports and in unbalanced competitions is less clear. Some evidences for home advantage has been identified in cross-country running (McCutcheon, 1984), wrestling (Gayton \& Langevin, 1992; McAndrew, 1992), World Cup alpine skiing (Bray \& Carron, 1993), speed skating (Koning, 2005) and boxing (Balmer, Nevill, \& Lane, 2005). By contrast, once the quality of the athletes has been accounted for, home advantage was not found to be a major influence on performance in individual "grand slam" tennis or "major" golf tournaments (Nevill et al., 1997).

\section{Team vs. Individual Sports Home Advantage}

More recent studies suggest that home advantage is a multifactorial phenomenon with many unknown aspects. For example, Balmer, Nevill, and Williams (2001) showed in a study on home advantage in the Winter Olympic Games that home advantage varies between team and individual events, as well as between events relying on differing scoring systems and between events with and without local facility variation. A significantly greater advantage has been identified for disciplines in which officials directly judge the outcomes, probably due to disproportionately high scoring for home competitors, and for disciplines that inherently entail the possibility of local variation in the facilities (Figure 1). Clarke (2000) reported that 17 out of 19 hosting Nations of Olympic Games achieved its better historic performance as home Nation. The higher economic inversion made by hosting Nation, the possibility of competing in all Olympic

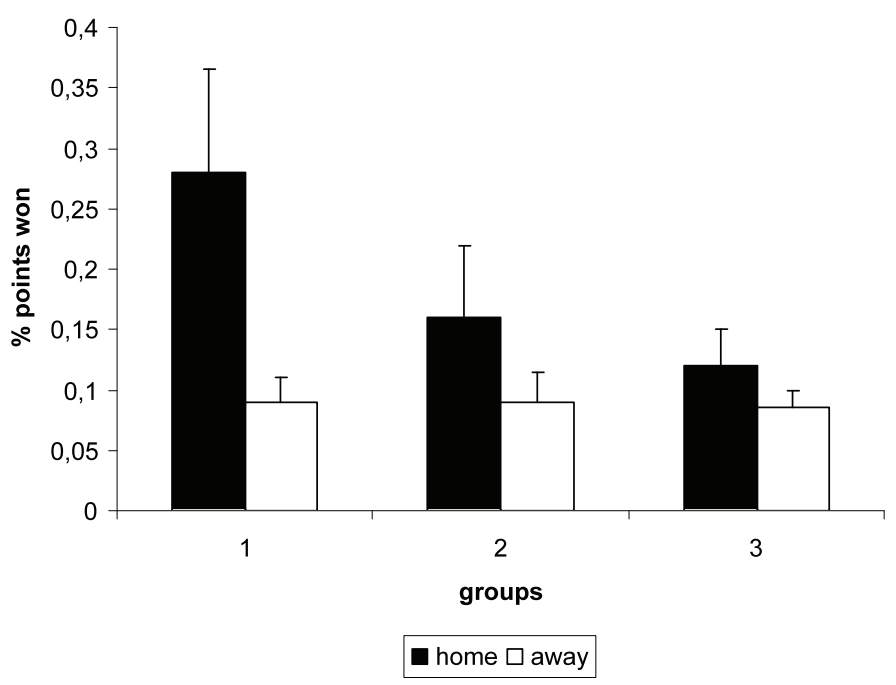

Figure 1. Differences between the proportions of points won at home and away by nations hosting Olympic Winter Games for three groups of sports: 1) subjectively judged sports, 2) sports with local facility variations and 3) objectively judged sports.

* Sport performance is expressed as percentage of won points from total. Gold medal $=3$ points, silver medal $=2$ points, bronze medal $=1$ point.

Source: Adapted from Balmer et al. (2001). 
disciplines and the home advantage could explain these findings. In fact, home advantage seems to be associated with sports' discipline. Thus, Balmer, Nevill, and Williams (2003) analysed the Summer Olympic Games and found that team sports, which have higher spectator attendance and subjectively judged sports, like gymnastics or boxing, yielded higher performance at home. However, objectively judged sports, like athletics or weightlifting, did not show home advantage (Figure 2).

\section{Causes of home advantage}

There have been four reviews that have provided a general overview of the home advantage effect in sports: those of Courneya and Carron (1992), Nevill and Holder (1999), Carron et al. (2005) and Pollard (2006a). In addition to providing an overview of prior research, three of these reviews suggested frameworks or models to highlight and organize the major components involved in the home advantage process which interact with each other in ways that vary from sport to sport. According to those models, the most relevant causes of home advantage are (i) the influence of the crowd, (ii) the familiarity with the context, (iii) travel fatigue, (iv) rule factors that favor the home athlete/team, and (v) territoriality (Figure 3). These factors could influence the psychological and behavioural states of athletes, coaches, and referees, partially explaining the home advantage found in empirical studies.

\section{Crowd and Home Advantage}

The crowd is one of the main factors thought to be responsible for home advantage due to differences in conditions between home and away (Agnew \& Carron, 1994; Nevill et al., 1999). Researchers have tried to determine whether the home advantage is a function of crowd size (Dowie, 1982; Nevill et al., 1996), crowd density (Agnew \& Carron, 1994; Pollard, 1986) and/or crowd noise (Nevill, Balmer, \& Williams, 2002). Despite mixed results (Nevill \& Holder, 1999; Pollard, 2006a), evidence suggests that the influence of the crowd depends on the kind of sport and on other mediating factors, such as referees' decisions in subjectively judged sports like soccer. In fact, several studies have shown that referees

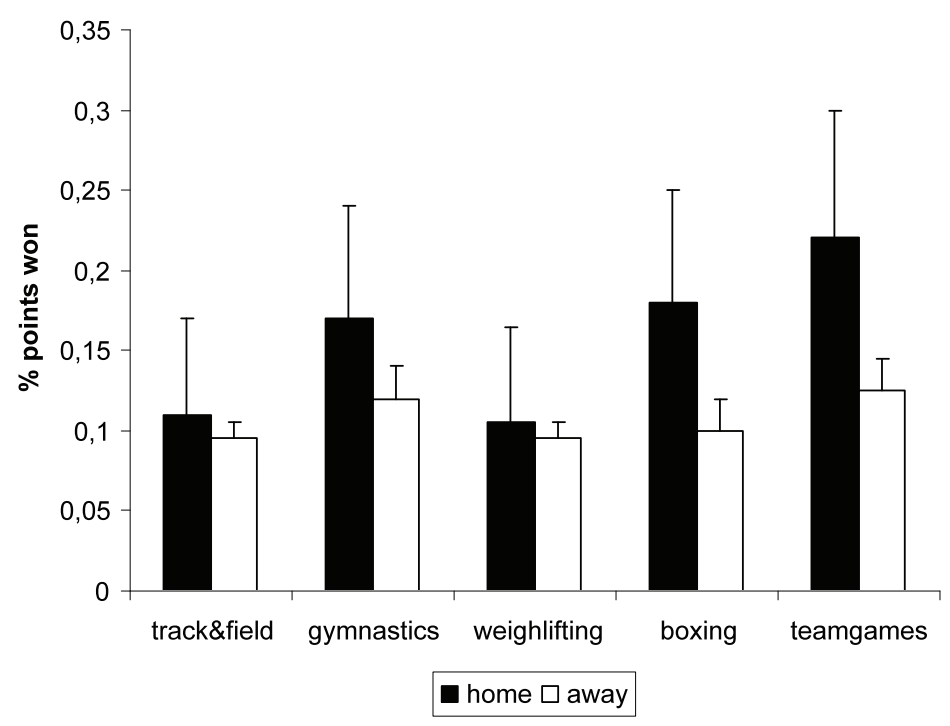

Figure 2. Percentage of points won at home and away ( \pm standard error of the estimate) by nations hosting Summer Olympic Games.

* Sport performance is expressed as percentage of won points from total. Gold medal $=3$ points, silver medal $=2$ points, bronze medal $=1$ point.

Source: Adapted from Balmer et al. (2003). 
may be influenced by a large crowd to favor the home team (Downward \& Jones, 2007; Nevill et al., 2002; Sutter \& Kocher, 2004). Obviously, size, intensity of support or proximity to the field play are factors able to influence mood states or even attention level of athletes, coaches and referees, affecting sport performance and partially explaining the home advantage phenomenon.

\section{Facility Familiarity and Home Advantage}

Familiarity with the home playing facility or even with the local climatic conditions and with altitude, are plausible contributing causes of home advantage. However, most studies have focused on sports with relatively little potential for variation in local conditions, in contrast to other sports like alpine skiing. Dowie (1982) and Pollard (1986) suggested that familiarity with the facility is one cause of home advantage. Subsequently, Clarke and Norman (1995) and Barnett and Hilditch (1993) observed that professional soccer teams in England that played on unusually large or small pitches or on artificial surfaces might have benefited from a slightly increased home advantage. There is also some evidence that familiarity with local conditions may contribute to the advantage gained by host countries in the Winter and Summer Olympic Games (Figure 2) (Balmer et al., 2003). In fact, Balmer et al. (2001) identified a significantly greater advantage for disciplines that have the possibility of a local variation in the facilities (Figure 1). In this respect, Pollard (2002) estimated that about $24 \%$ of the advantage of playing at home may be lost when a team relocates to a new facility, but other studies have suggested that there are no effects or slightly positive effects associated with moving to a new facility (Loughead, Carron, Bray, \& Kim, 2003; Moore \& Brylinsky, 1995; Watson \& Krantz, 2003). In any case, the primary findings tend to indicate only small effects for the contribution of familiarity with local conditions (e.g., physical characteristics of the stadium, distraction during games, disruption to the normal pre-game preparation, etc.) to the home advantage effect. In any case, this relative advantage from familiarity with the competitive context could justify the economic investment from competition managers to improve their athletes' sport performance.

\section{Travels and Home Advantage}

The travels associated with competition may contribute to the home advantage because of the fatigue that athletes suffer, and because of the disruption of the normal routine. Travel factors that have been analyzed include the distance between the two facilities (Clarke \& Norman, 1995; Snyder $\&$ Purdy, 1985), the number of time zones crossed (Balmer et al., 2001; Pace \& Carron, 1992) and the impact of jet-lag (Jehue, Street, \& Huizenga,

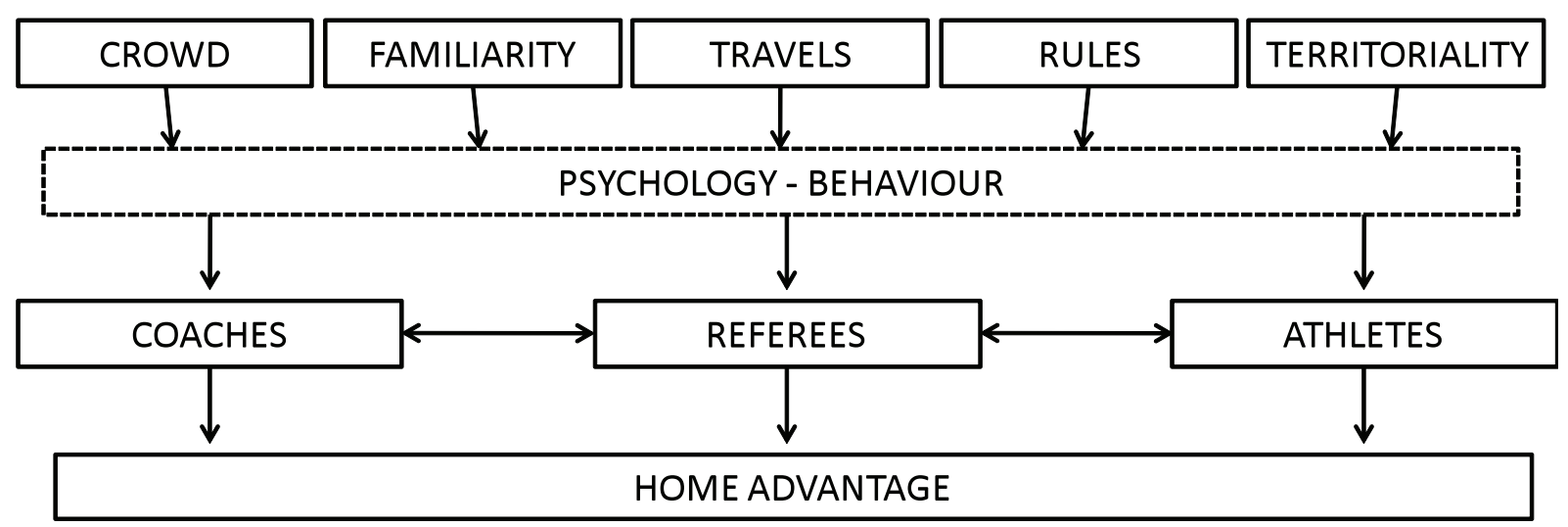

Figure 3. Conceptual framework of the home advantage. Source: Own work. 
1993; Recht, Lew, \& Schwartz, 2003). The results indicate a weak or no significant effect of travel duration and distance on sports performance, but home advantage is reduced in local derbies where no travel is involved (Carron et al., 2005; Nevill \& Holder, 1999; Pace \& Carron, 1992; Pollard, 2006a). Anyway, despite the athletes' common beliefs, only a small proportion of the variance in home advantage can be explained by travel-related factors and, therefore, competition is only slightly disrupted by including long travel distances for competitive events.

\section{Rules and Home Advantage}

The rules in some sports (e.g., the last offensive opportunity in baseball belongs to the home team) may provide home advantage; however, studies have generally been focused on referee bias. Referee bias has been identified as a cause of the home advantage. In fact, several studies have found a bias of referees in favor of the home team/athlete (more free kicks, fewer yellow and red cards, more extra time, higher scores, etc.) rather than a bias against the away team/athlete (Ansorge \& Scheer, 1988; Boyko, Boyko, \& Boyko, 2007; Downward \& Jones, 2007; Nevill et al., 2002; Seltzer \& Glass, 1991; Sutter \& Kocher, 2004; Whissell, Lyons, Wilkinson, \& Whissell, 1993).

In team sports, there is evidence to suggest that a large crowd may affect the decisions of match referees, either by the noise they make or by the referees' perception that they are being monitored, and this may be a potential contributing factor to the home advantage phenomenon (Nevill \& Holder, 1999; Nevill et al., 1996; Nevill et al., 2002). In any case, there is a debate about the importance of this factor because Jones, Bray, and Bolton (2001) in cricket and Dennis, Carron, and Loughead (2002) in ice hockey found no effect from referee bias. It would appear that, if referee bias does have an effect on the home advantage, it is greater in sports in which there is a high degree of subjective evaluation. For the Winter Olympic Games, Balmer et al. (2001), according to Seltzer and Glass (1991) and Whissell et al. (1993), identified a significantly greater advantage for disciplines in which officials directly judge outcomes, probably due to disproportionately high scoring for home competitors (Figure 1). Similarly, Balmer et al. (2003), after analysing the Summer Olympic Games, found that subjectively judged sports, like gymnastics or boxing, generated higher performance at home in contrast to objectively judged sports, like athletics or weightlifting (Figure 2). The home advantage is probably derived from referee bias and is mediated by different factors depending on the sport, such as the crowd and the political and nationalistic feelings. Thus, specific training protocols to improve referees' ability to handle psychological stress could minimize home advantage phenomenon by reducing subjective decisions.

\section{Territoriality and Home Advantage}

Evidence has shown that having to defend the home ground evokes territoriality, that is, a protective response to an invasion of one's perceived territory (Neave \& Wolfson, 2003; Pollard, 2006b). Pollard and Pollard (2005a, 2006b) have shown that the clear variations in soccer home advantage can be largely explained by geographical location (Figure 5). The Balkan nations of southeastern Europe, especially Albania and Bosnia, have shown a larger home advantage than elsewhere (e.g., Baltic republics, Scandinavia, and the British Isles).

It is likely that physical location of this territory, between mountains, and its historic ethnic and religious conflicts are responsible for an increased sense of territoriality. Similar findings have been shown in other geographical locations such Asia and Latin America. In relation to the sense of territoriality, Mazur and Booth (1998) determined that higher testosterone levels are linked to aggressive and assertive behaviours, both of which are very important in competitive sports. In fact, higher concentrations of salivary testosterone have been found in players before home games than before away or training games (Carre, 2009; Neave \& Wolfson, 2003). The exact manner in which this finding might affect performance awaits further research. Anyway, we consider that coaches and 
sport psychologist should promote those territoriality feelings in order to achieve more adequate psychological competitive conditions that ensure higher performance levels.

\section{Psychological Implications of Home Advantage}

Aside from the identified causes of home advantage in competitive sports, game location seems to have an influence on the psychological and behavioural states of (i) coaches, (ii) referees, and (iii) athletes, which contribute to higher performance levels at local facilities. Despite little is known about the role that psychological states, including mood, anxiety, confidence and efficacy may play in the home advantage, we have found some scientific evidence re- lated to those physiological states, confirming that this may be a potentially fruitful area of research.

\section{Coaches and Home Advantage}

Some studies suggest that strategic and tactical coaching decisions are influenced by game location and by the crowd. In fact, coaches tend to adopt more offensive strategies at home than away, which could partially explain home advantage in sport (Dennis \& Carron, 1999).

\section{Referees and Home Advantage}

A bias of referees in favor of the home team/athlete, especially in sports with a high degree of subjective evaluation, has been identified in several studies.

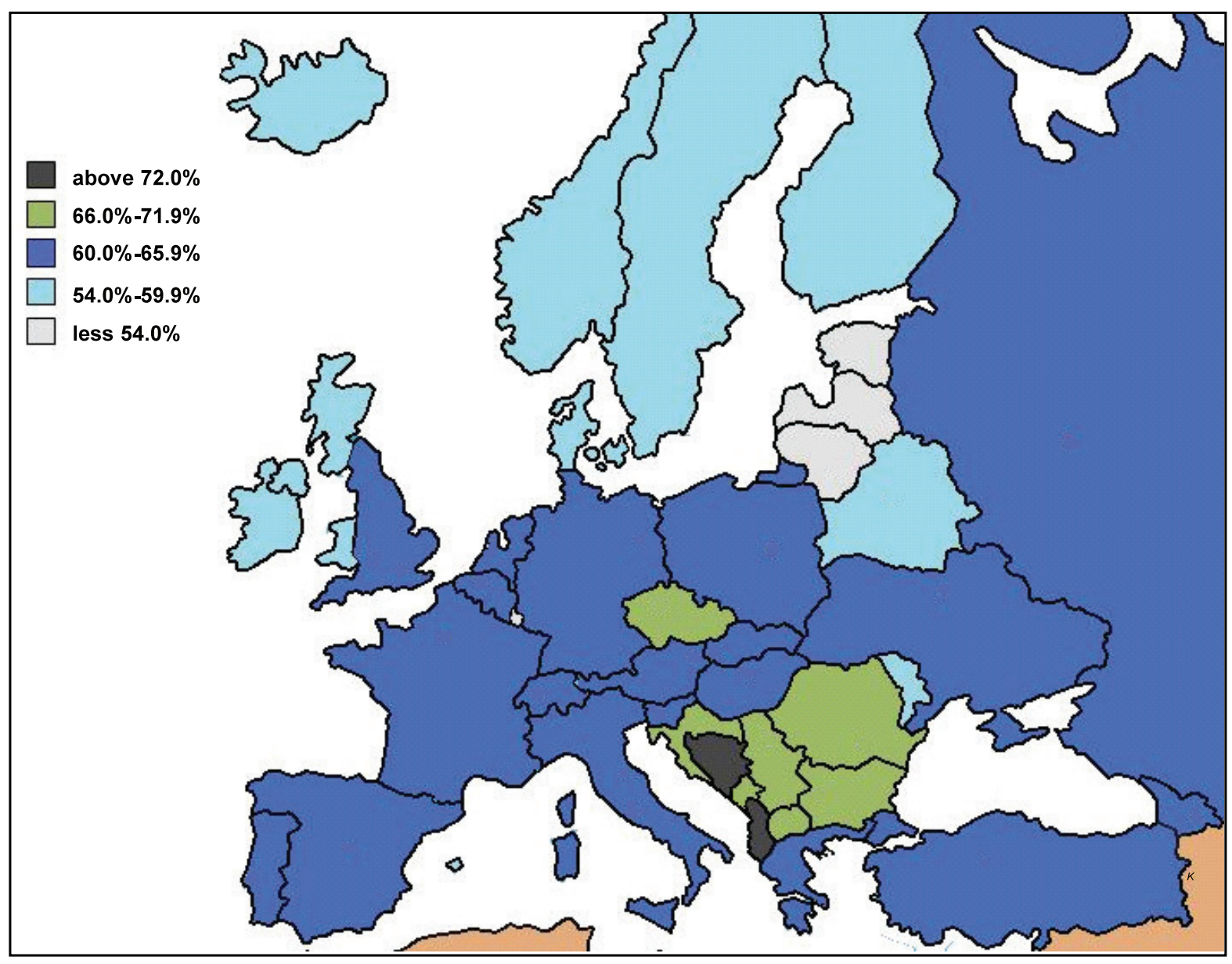

Figure 4. Map of Europe showing home advantage in the national soccer league of each country. Source: Adapted from Pollard (2006b). 
Theorists have suggested that the home crowd's may influence referees' decisions by increasing anxiety and decreasing self-confidence, which could partiality explain the home advantage phenomenon (Ansorge \& Scheer, 1988; Boyko et al., 2007; Downward \& Jones, 2007; Nevill et al., 2002; Seltzer \& Glass, 1991; Sutter \& Kocher, 2004; Whissell et al., 1993).

\section{Athletes and Home Advantage}

Some studies suggest that athletes experience more positive psychological states when competing at home versus away, thus resulting in superior home performances (Carre et al., 2006; Terry et al., 1998; Thuot et al., 1998; Waters \& Lovell, 2002). For example, Terry et al. (1998) found that rugby union players had more positive mood profiles, lower anxiety, and higher self-confidence prior to their home games than prior to their away games. Similarly, Thuot et al. (1998) found lower levels of somatic anxiety and higher levels of self-confidence when high school basketball players competed at home. Despite the evidence, the influence of game location on the psychological states of athletes remains inconclusive due to some contradictory findings (Bray \& Martin, 2003; Bray et al., 2000; Carron et al., 2005; Duffy \& Hinwood, 1997; Neave \& Wolfson, 2003; Polman et al., 2007). For example, Duffy and Hinwood (1997) found no differences in the pre-performance anxiety levels reported by professional soccer players competing at home versus away. Similarly, Bray and Martin (2003) reported no differences in pre-competition levels of anxiety or self-confidence at home, compared to away amongst junior alpine skiers. In any case, the research results must be interpreted cautiously because, in these studies, individual psychological states were examined in relation to team performance. Thus, it is impossible to determine whether those athletes who had a better psychological profile at home also performed better at home.

\section{Conclusion}

The existence and magnitude of home advantage has been established by several studies. However, scientists have failed to isolate a dominant factor that is responsible for this phenomenon. According to available scientific literature, it is likely that a number of individual factors interact with each other and influence the psychological and behavioural states of coaches, referees, and athletes in a manner yet to be established. Thus, home advantage is probably the result of their combined effect and the influence of other less explored factors such as competition pressure, athletes' salaries or even ticket prices.

Coaches and managers could use the available information about home advantage to adopt strategies that would abrogate the negative influence of a hostile crowd; to create routines that generate a familiar ambience, even in away competitions; to prevent the fatigue associated with long travels; to take into account a possible referee bias; to evoke territoriality; to promote positive psychological and behavioural states; and to make optimal coaching decisions to improve the performance level of their athletes.

Currently, few studies have investigated the psychological and behavioral states of coaches, referees and athletes in home and away competitions. Therefore, future investigations should focus on factors that influence these psychological states that can have a profound impact on sport performance, having consequences for all the involved elements: managers, crowd, media, athletes, coaches, sport psychologists, referees, etc.

\section{References}

Adams, R. D., \& Kupper, S. J. (1994). The effect of the expertise on peak performance: The case of home-field advantage. Journal of Sport Behavior, 17(2), 108-119.

Agnew, G. A., \& Carron, A. V. (1994). Crowd effects and the home advantage. Journal of Sport Psycho$\log y, 25(1), 53-62$. 
Ansorge, C. J., \& Scheer, J. K. (1988). International bias detected in judging gymnastic competition at the 1984 Olympic games. Research Quarterly for Exercise and Sport, 59(2), 103-107.

Balmer, N. J., Nevill, A. M., \& Lane, A. M. (2005). Do judges enhance home advantage in European championship boxing? Journal of Sports Sciences, 23(4), 409-416.

Balmer, N. J., Nevill, A. M., \& Williams, A. M. (2001). Home advantage in the Winter Olympics (19081998). Journal of Sports Sciences, 19(2), 129-139.

Balmer, N. J., Nevill, A. M., \& Williams, A. M. (2003). Modelling home advantage in the Summer Olympic Games. Journal of Sports Sciences, 21(6), 469 . 478.

Barnett, V., \& Hilditch, S. (1993). The effect of an artificial pitch surface on home team performance in football (soccer). Journal of the Royal Statistical Society, 156(1), 39-50.

Boyko, R. H., Boyko, A. R., \& Boyko, M. G. (2007). Referee bias contributes to home advantage in English Premiership football. Journal of Sports Sciences, 25(11), 1185-1194.

Bray, S. R. (1999). The home advantage from an individual team perspective. Journal of Applied Sport Psychology, 11(1), 116-125.

Bray, S. R., \& Carron, A. V. (1993). The home advantage in alpine skiing. Australian Journal of Science and Medicine in Sport, 25(4), 76-81.

Bray, S. R., \& Martin, K. A. (2003). The effect of competition location on individual athlete performance and psychological states. Psychology of Sport and Exercise, 4(2), 117-123.

Bray, S. R., Martin, K. A., \& Widmeyer, W. N. (2000). The relationship between evaluative concerns and sport competition state anxiety among youth skiers. Journal of Sports Sciences, 18(5), 353-361.

Bray, S. R., Obara, J., \& Kwan, M. (2005). Batting last as a home advantage factor in men's NCAA tournament baseball. Journal of Sports Sciences, 23(7), 681-686.

Brown, T. D., Van Raalte, J. L., Brewer, B. W., Winter, C. R., \& Cornelius, A. A. (2002). World cup soccer home advantage. Journal of Sport Behavior, 25(2), 134-144.
Brutsaert, T. D., \& Parra, E. J. (2006). What makes a champion? Explaining variation in human athletic performance. Respiration Physiology $\mathbb{E}$ Neurobiology, 151(2-3), 109-123.

Carre, J. M. (2009). No place like home: Testosterone responses to victory depend on game location. American Journal of Human Biology, 21(3), 392-394.

Carre, J., Muir, C., Belanger, J., \& Putnam, S. K. (2006). Pre-competition hormonal and psychological levels of elite hockey players: Relationship to the "home advantage". Physiology and Behavior, 89(3), 392-398.

Carron, A. V., Loughhead, T. M., \& Bray, S. R. (2005). The home advantage in sport competitions: Courneya and Carron's (1992) conceptual framework a decade later. Journal of Sports Sciences, 23(4), 395-407.

Clarke, S. R. (2000). Home advantage in the Olympic games. In Proceedings of the Fifth Australian Conference on Mathematics and Computers in Sport (pp. 43-51). Sydney: University of Technology.

Clarke, S. R. (2005). Home advantage in the Australian Football League. Journal of Sports Sciences, 23(4), 375-385.

Clarke, S. R., \& Norman, J. M. (1995). Home advantage of individual clubs in English soccer. The Statistician, 44(4), 509-521.

Courneya, K. S., \& Carron, A. V. (1992). The home advantage in sport competitions: A literature review. Journal of Sport and Exercise Psychology, 14(1), 13-27.

Davids, K., \& Baker, J. (2007). Genes, environment and sport performance: Why the nature-nurture dualism is no longer relevant. Sports Medicine, 37(11), 961-980.

Dennis, P. W., \& Carron, A. V. (1999). Strategic decisions of ice hockey coaches as a function of game location. Journal of Sports Sciences, 17(4), 263-268.

Dennis, P. W., Carron, A. V., \& Loughead, T. M. (2002). The relationship between game location and decisions by National Hockey League officials. Avante, 8(2), 67-73.

Dowie, J. (1982). Why Spain should win the World Cup. New Scientist, 94(10), 693-695. 
Downward, P., \& Jones, M. (2007). Effects of crowd size on referee decisions: Analysis of the FA Cup. Journal of Sports Sciences, 25(14), 1541-1545.

Duffy, L. J., \& Hinwood, D. P. (1997). Home field advantage: Does anxiety contribute? Percept Mot Skills, 84(1), 283-286.

Gayton, W. F., \& Langevin, G. (1992). Home advantage: Does it exist in individual sports? Perceptual and Motor Skills, 74(3, Pt 1), 706.

Jehue, R., Street, D., \& Huizenga, R. (1993). Effect of time zone and game time changes on team performance: National Football League. Medicine and Science in Sports and Exercise, 25(1), 127-131.

Jones, M. V., Bray, S. R., \& Bolton, L. (2001). Game location and officiating bias in English Club Cricket. Perceptual and Motor Skills, 93(2), 359-362.

Koning, R. H. (2005). Home advantage in speed skating: Evidence from individual data. Journal of Sports Sciences, 23(4), 417-427.

Loughead, T. M., Carron, A. V., Bray, S. R., \& Kim, A. (2003). Facility familiarity and the home advantage in professional sports. International Journal of Sport Psychology and Exercise Psychology, 1(3), 264-274.

Maughan, R. J. (2005). The limits of human athletic performance. Annals of Transplantation, 10(4), 52-54.

Mazur, A., \& Booth, A. (1998). Testosterone and dominance in men. Behavioral and Brain Sciences, 21(3), 353-397.

McAndrew, F. T. (1992). The home advantage in individual sport. Journal of Social Psychology, 133(3), 401-403.

McCutcheon, L. E. (1984). The home advantage in high school athletics. Journal of Sport Behavior, 7(4), 135-138.

Moore, J. C., \& Brylinsky, J. (1995). Facility familiarity and the home advantage. Journal of Sport Behavior, 18(4), 302-311.

Morton, R. H. (2006). Home advantage in southern hemisphere rugby union: National and international. Journal of Sports Sciences, 24(5), 495-499.

Neave, N., \& Wolfson, S. (2003). Testosterone, territoriality, and the 'home advantage'. Physiology and Behavior, 78(2), 269-275.
Nevill, A., Balmer, N., \& Williams, M. (1999). Crowd influence on decisions in association football. Lancet, 353(9162), 1416.

Nevill, A. M., Balmer, N. J., \& Williams, A. M. (2002). The influence of crowd noise and experience upon refereeing decisions in football. Psychology of Sport and Exercise, 3(4), 261-272.

Nevill, A. M., \& Holder, R. L. (1999). Home advantage in sport: An overview of studies on the advantage of playing at home. Sports Medicine, 28(4), 221-236.

Nevill, A. M., Holder, R. L., Bardsley, A., Calvert, H., \& Jones, S. (1997). Identifying home advantage in international tennis and golf tournaments. Journal of Sports Sciences, 15(4), 437-443.

Nevill, A. M., Newell, S. M., \& Gale, S. (1996). Factors associated with home advantage in English and Scottish soccer matches. Journal of Sports Sciences, 14(2), 181-186.

Pace, A., \& Carron, A. V. (1992). Travel and the home advantage. Canadian Journal of Sport Sciences, 17(1), 60-64.

Page, L., \& Page, K. (2007). The second leg home advantage: Evidence from European football cup competitions. Journal of Sports Sciences, 25(14), 1547-1556.

Polman, R., Nicholls, A. R., Cohen, J., \& Borkoles, E. (2007). The influence of game location and outcome on behaviour and mood states among professional rugby league players. Journal of Sports Sciences, 25(13), 1491-1500.

Pollard, R. (1986). Home advantage in soccer: A retrospective analysis. Journal of Sports Sciences, 4(3), 237-248.

Pollard, R. (2002). Evidence of a reduced home advantage when a team moves to a new stadium. Journal of Sports Sciences, 20(12), 969-973.

Pollard, R. (2006a). Home advantage in soccer: Variations in its magnitude and a literature review of the inter-related factors associated with its existence. Journal of Sport Behavior, 29(2), 169-189.

Pollard, R. (2006b). Worldwide regional variations in home advantage in association football. Journal of Sports Sciences, 24(3), 231-240.

Pollard, R., \& Pollard, G. (2005a). Home advantage in soccer: A review of its existence and causes. International Journal of Soccer and Science, 3(1), 28-38. 
Pollard, R., \& Pollard, G. (2005b). Long-term trends in home advantage in professional team sports in North America and England (1876-2003). Journal of Sports Sciences, 23(4), 337-350.

Recht, L. D., Lew, R. A., \& Schwartz, W. J. (2003). Baseball teams beaten by jet-lag. Nature, 377(6550), 583.

Seltzer, R., \& Glass, W. (1991). International politics and judging in Olympic skating events: 1968-1988. Journal of Sport Behavior, 14(3), 189-200.

Smith, D. J. (2003). A framework for understanding the training process leading to elite performance. Sports Medicine, 33(15), 1103-1126.

Snyder, E. E., \& Purdy, D. A. (1985). The home advantage in collegiate basketball. Sociology of Sport Journal, 2(4), 352-356.

Steenland, K., \& Deddens, J. A. (1997). Effect of travel and rest on performance of professional basketball players. Sleep, 20(5), 366-369.

Sutter, M., \& Kocher, M. G. (2004). Favoritism of agents - the case of referees' home bias. Journal of Economic Psychology, 25(4), 461-469.

Terry, P. C., Walrond, N., \& Carron, A. V. (1998). The influence of game location on athletes' psychological states. Journal of Science and Medicine in Sport, 1(1), 29-37.

Thomas, S., Reeves, C., \& Davies, S. (2004). An analysis of home advantage in the English Football
Premiership. Perceptual and Motor Skills, 99(3 Pt 2), 1212-1216.

Thuot, S. M., Kavouras, S. A., \& Kenefick, R. W. (1998). Effect of perceived ability, game location, and state anxiety on basketball performance. Journal of Sport Behavior, 21(3), 311-321.

Waters, A., \& Lovell, G. (2002). An examination of the homefield advantage in a professional English soccer team from a psychological standpoint. Football Studies, 5(1), 46-59.

Watson, J. C., 2nd, \& Krantz, A. J., 3rd (2003). Home field advantage: New stadium construction and team performance in professional sports. Perceptual and Motor Skills, 97(3 Pt 1), 794-796.

Whissell, R., Lyons, S., Wilkinson, D., \& Whissell, C. (1993). National bias in judgments of Olympiclevel skating. Perceptual and Motor Skills, 77(2), 355-358.

Williams, A. G., \& Folland, J. P. (2008). Similarity of polygenic profiles limits the potential for elite human physical performance. Journal of Physiology, 586(1), 113-121.

Wolfson, S., Wakelin, D., \& Lewis, M. (2005). Football supporters' perceptions of their role in the home advantage. Journal of Sports Sciences, 23(4), 365 374. 
